\title{
Caustic Digestive Lesions in Adults: Epidemiological, Endoscopic and Therapeutic Aspects at Idrissa Pouye General Hospital (Dakar, Senegal)
}

\author{
Mamadou Ngoné Gueye*, Cheikh Ahmadou Bamaba Cissé, Gnagna Diouf, Salamata Diallo, Mame Aïssé Thioubou, \\ Marème Polèle Fall, Marie Louise Bassène, Daouda Dia and Mouhamadou Mbengue
}

Cheikh Anta Diop University of Dakar, drissa Pouye General Hospital, Dakar, Senegal

Submission: July 07, 2020; Published: August 13, 2020

*Corresponding author: Mamadou Ngoné Gueye, Cheikh Anta Diop University of Dakar, drissa Pouye General Hospital, Dakar, Senegal

\section{Abstract}

Introduction: Ingestion of caustic products is a diagnostic and therapeutic emergency. Its severity is related to the risk of death and digestive functional sequelae. Common in children, following accidental ingestion, many studies have been devoted to it in the pediatric environment. However, data on adult populations are rare in our context. The aim of this work was to describe the profile of patients hospitalized for caustic ingestion, the context of occurrence, the endoscopic lesions observed, their evolution and their therapeutic modalities.

Patients and methods: This was a descriptive retrospective study in the Hepato-Gastroenterology Department of the Idrissa Pouye General Hospital (HOGIP) over a period of 8 years (March 2008-March 2016). The records of patients over 15 years old, hospitalized for caustic ingestion were collected. The age, sex, circumstances of occurrence, nature of the caustic, consultation and endoscopy time, endoscopic lesions and their therapeutic modalities were studied.

Results: Of the 2750 patients hospitalized during the study period, 25 were admitted for ingestion of digestive caustic products, corresponding to a prevalence of $0.9 \%$. Three records were not searched. The following data were obtained from the analysis of 22 records. The mean age was 36.5 years (range: 16-82 years) with a sex ratio of 0.7 (13 females). Ingestion of the caustic was voluntary in 16 cases (11 women). The main motivations for the women were family conflicts. A regular intake of hallucinogenic substances (Indian hemp) was noted in $80 \%$ of men who voluntarily ingested a caustic product. Caustic soda was the product most often incriminated. The average quantities of caustic ingested were respectively $100 \mathrm{cc}$ and $300 \mathrm{cc}$ depending on whether the ingestion was accidental or voluntary. The median consultation time was 5 hours (30min-28d) and the median endoscopy time was 48 hours (16h-70d). The main acute esophageal lesions objectified were grade IIB (46.8\%) and IIIA (37.3\%) according to Di Costanzo's classification. At the gastric level, grade I and IIa lesions were present in 36.4\% and $43 \%$ of cases respectively. Control endoscopy revealed esophageal or gastric stenosis in 8 cases (36.4\%) and 2 cases (9\%) respectively. Therapeutically, a total diet was instituted in all patients. The average duration of the diet was 15 days ( 2 days - 21 days). Parenteral nutrition was introduced in 5 patients (22.7\%). PPI therapy and rehydration were the standard treatment in all patients. Eight patients received endoscopic esophageal dilations. The mean number of dilation sessions was 4 (range: 2-11). Gastroentero anastomosis was performed in 2 patients. One case of death was recorded at D7 of hospitalization following septic shock in a patient with grade IIIB esogastric lesions of Di Costenzo.

Conclusion: The ingestion of caustic products in the hospitalization unit of the Hepato-Gastroenterology Department of Idrissa Pouye General Hospital is more frequent in women, most often related to an attempt at autolysis in the context of family conflicts. In men, caustic ingestion generally occurs in the context of taking hallucinogenic products. Caustic soda is the product most often incriminated. Esophageal stenosis is the main sequelae.

Keywords: Caustic; Esophagitis; Gastritis; Adult; Caustic soda; Stenosis

\section{Introduction}

Ingestion of caustic products is a medical-surgical emergency. It is defined as the absorption through the digestive tract of one or more substances that have the capacity to destroy biological tissues by contiguity [1]. In Senegal, caustic digestive burns are a frequent emergency among children following accidental ingestion. Numerous studies have been devoted to it in pediatrics settings [2]. In adults, data are rare. The lesions observed are often severe in this population, since ingestion of caustic product generally occurs in the context of attempted autolysis. The 
severity of caustic burns is essentially related to the risk of death by digestive perforation and the dreaded functional sequelae they entail. The aim of this work was to describe the profile of patients hospitalized for caustic burns, the context in which they occurred, the endoscopic lesions observed, their evolution and their therapeutic modalities.

\section{Patients and Methods}

This was a retrospective study at the Hepato-Gastroenterology Department of the Grand Yoff General Hospital (HOGGY) over a period of 8 years (March 2008-March 2016). The records of patients over 15 years of age, hospitalized for caustic ingestion were collected. Records with incomplete information were not used. The age, sex, the circumstances in which caustic ingestion occurred, the nature and quantity of the product ingested, the time taken to consult and perform endoscopies, the endoscopic lesions and their therapeutic modalities were studied.

\section{Results}

Of the 2750 patients hospitalized during the study period, 25 were admitted for ingestion of digestive caustic products, corresponding to a prevalence of $0.9 \%$ (Figure 1 ). Three records were not retrieved. The following data were obtained from the analysis of 22 records. The mean age was 36.5 years (range: $16-82$ years) with a sex ratio of 0.7 (13 females). Ingestion of the caustic was voluntary in 16 cases $(72.7 \%)$, of which 11 were female (68.7\%).

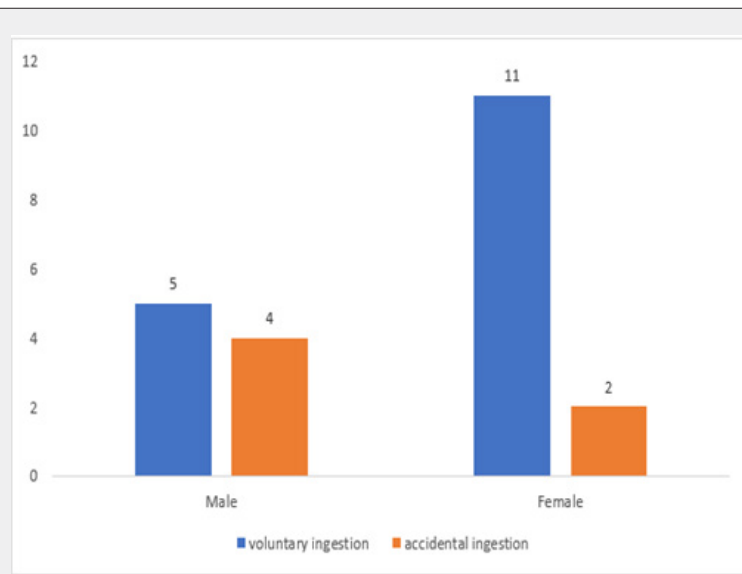

Figure 1: Distribution of patients by gender and circumstance of occurrence of caustic ingestion.

The main motivations among women were family conflicts. A regular intake of hallucinogenic substances, particularly Indian hemp, was noted in $80 \%$ of men who voluntarily ingested a caustic product. Caustic soda was the product most often incriminated (Figure 2). The average quantities of caustic ingested were respectively $100 \mathrm{cc}$ and $300 \mathrm{cc}$ depending on whether the ingestion was accidental or voluntary. The median time of consultation was 5 hours (30min-28d) and the median time for endoscopy was 48 hours (16h-70days). The main acute esophageal lesions objectified were grade IIB (46.8\%) and IIIA (37.3\%) according to Di Costanzo's classification. At the gastric level, grade I and IIa lesions were present in $36.4 \%$ and $43 \%$ of cases respectively. Five cases of stage IIa and IIb duodenitis were observed. Figure 3 shows the distribution of patients according to the severity of endoscopic lesions according to the Di Costanzo classification.

type of product caustic

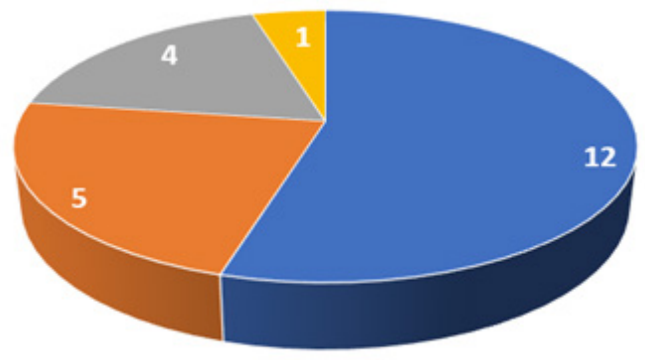

Figure 2: Distribution of patients by type of caustic ingredient ingested. 


\section{Severity of lesions according to Di Costanzo's classification}

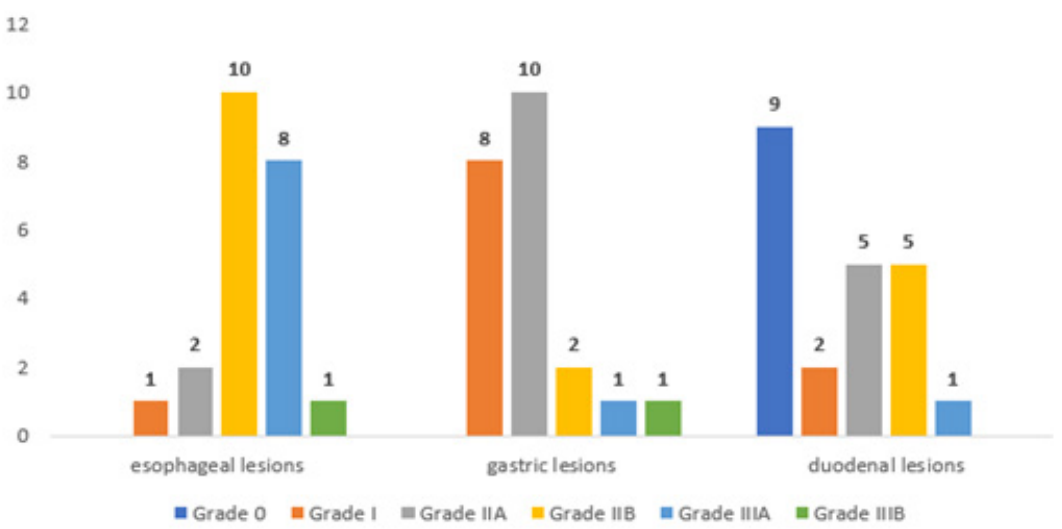

Figure 3: Distribution of patients by severity of endoscopic lesions according to Di costanzo's classification.

Therapeutically, a diet with a mean duration of 15 days (2d-21d) and injectable PPI therapy (esomeprazole $40 \mathrm{mg} \mathrm{X} \mathrm{2/d)}$ was instituted in all patients. Parenteral nutrition was initiated in 5 patients $(22.7 \%)$ and 17 patients $(77.2 \%)$ were started on antibiotics (ceftriaxone $2 \mathrm{~g} / \mathrm{d}$ ). A psychiatric consultation was made in all cases of voluntary ingestion of the caustic product. A follow-up endoscopy was performed on average 10 days after the first one in 16 cases $(72.7 \%)$ and noted regression of acute lesions in 13 cases. A second follow-up endoscopy was performed on average 1 month after the first in 12 cases (54.5\%). The second follow-up endoscopy showed esophageal stenosis in 8 cases (36.4\%) and gastric stenosis in 2 cases (9\%). Eight patients benefited from endoscopic esophageal dilations with Savary Gillard dilator. The mean number of dilation sessions was 4 (extremes: 2-11). Gastroentero anastomosis was performed in 2 patients. One case of death was recorded at D7 of hospitalization following septic shock in a patient with grade IIIB esogastric lesions of Di Costenzo.

\section{Discussion}

Ingestion of caustic material is a diagnostic and therapeutic emergency. The occurrence of a severe burn can be lifethreatening and functionally prognostic, with mortality rates approaching 10\% [3]. Two contexts must be distinguished: involuntary ingestion, most often in the context of a domestic accident, and voluntary ingestion generally occurring in the context of attempted autolysis. The latter is the most frequent circumstance of occurrence in adults. In our series, ingestion was voluntary in 16 patients including 11 women (68.7\%). This female predominance was reported in series in the Maghreb [4] and in the West [5]. In sub-Saharan Africa and the Maghreb, family conflicts are the main reasons for voluntary ingestion of caustic ingestion in women [6,7]. In various Western series, economic difficulties were the primary reason cited [8]. Hallucinogenic products, especially Indian hemp, were found in
$80 \%$ of men who voluntarily ingested caustic. Several studies have demonstrated a relationship between the level of cannabis use and suicidal ideation/attempts $[9,10]$. The median time to complete the endoscopy was 48 hours in our study. In other series in sub-Saharan Africa, overlapping times were reported $[11,12]$. In France, Rodriguez et al. reported a completion time of 06 hours [5]. This long delay in the performance of endoscopy in our regions may be linked to the non-availability of digestive endoscopy in certain regions. The Société Française d'Endoscopie Digestive (SFED) recommends performing endoscopy within 6 to 24 hours after ingestion. Beyond 24 hours, endoscopy exposes to a greater risk of perforation in case of severe lesions. Although there are few precise data on this point, it can be considered that endoscopy is not recommended beyond 24 hours after exposure to caustic, and in this case should be very cautious and if possible under sedation [13].

Therapeutically, only 5 patients received parenteral nutrition. In sub-Saharan Africa, the high cost of pockets of parenteral nutrition limits their access. This is at the origin of sometimes severe nutritional disorders increasing morbidity and mortality in this area. In the evolution, 8 patients presented an esophageal stenosis. Dilatation with Savary candles lifted the stenosis on average after dilatation sessions. However, these patients are at risk of squamous cell carcinoma 15 to 20 years after exposure, requiring long-term endoscopic follow-up every one to three years, particularly when the scarred esophagus is left in place.

\section{Conclusion}

The ingestion of caustic products in the gastroenterology department of the idrissa Pouye general hospital is more frequent in women, most often linked to an attempt at autolysis in the context of family conflicts. In men, ingestion of caustic products generally occurs in the context of taking hallucinogenic products. Caustic soda is the product most often incriminated. The lesions often 
progress to stenosis requiring iterative sessions of endoscopic dilatations. These lesions due to their pre-neoplastic nature will have to be monitored as part of a screening programme.

\section{References}

1. Ertekin C, Alimoglu O, Akyildiz H, Guloglu R, Taviloglu K (2004) The results of caustic ingestions. Hepatogastroenterology 51(59): 13971400 .

2. F Ly, B Camara, F Ngomna, A Sakho Kane, A Sall Diouf (2019) Intoxications aiguës au service de pédiatrie du Centre Hospitalier National (CHN) de Pikine. A propos de 34 cas colligés. Médecine d'Afrique Noire 6604: 200-209.

3. Fieuxa F, Chiricab M, Villac A, Lossera M R, Cattanb P (2009) Ingestion de produits caustiques chez l'adulte. Réanimation 18: 606-616.

4. Oumnia N, Lahcene M, Tebaibia A, Matougui N, Boudjella MA (2009) Épidémiologie et évolution des brûlures caustiques du tube digestif supérieur: à propos de 483 cas. Journal africain d'hépato-gastroentérologie 3(3): 130-136.

5. Rodriguez A, Thumerel M, Delcambre F, Velly JF, Jougon J (2013) Proposition de recommandations concernant la prise en charge thérapeutique des lésions œsophagiennes et gastriques après ingestion de caustique chez l'adulte. Expérience bordelaise au cours des 6 dernières années chez 59 patients. Chirurgie thoracique cardio-vasculaire 17(3) 139-150.
6. Mohamed Maniboliot Soumah, Brice Angwé Eboué Mor Ndiaye, Mamadou Lamine Sow (2013) Aspects épidémiologiques du suicide à Dakar Pan African Medical Journal 15: 10.

7. Latifa Amiar, Abdelmajid Soulaymani, Ahmed Aarab, Abdelrhani Mokhtari, Rachida Soulaymani (2016) Aspects Épidémiologiques des Suicides et des Tentatives de Suicide par Intoxication au Maroc. European Journal of Scientific Research 140(3): 282-293.

8. Frey P (2001) Eude épidémiologique du suicide en région toulousaine dans la période de 1979-1999. Thèse Méd Toulouse 1032.

9. H Chabrol, M Choquet, J Costentin (2006) Le cnnabis, ses risques à l'adolescence. Editions Ellipse, Paris, pp. 142.

10. Costentin J (2006) Halte au cannabis, Editions Odile Jacob, Paris, pp. 264.

11. Bassène M L, Diouf M L, Dia D, Mbengue M, Halim A (2012) Lésions caustiques digestives: apport de l'endoscopie dans le diagnostic et le traitement dans le centre d'endoscopie du CHU Aristide Le Dantec. Journal Africain d'Hépato-Gastroentérologie 6(3): 179-182.

12. Martins OT, Ezekiel 00, Oladapo S (2009) Chemical injuries of the oesophagus: aetiopathological issues in Nigeria. Journal of Cardiothoracic Surgery 4(1): 56-61.

13. Lachaux A, Mas E, Breton A, Barange K (2011) Consensus en endoscopie digestive: prise en charge des œsophagites caustiques. Acta Endosc 41: 303-308. 